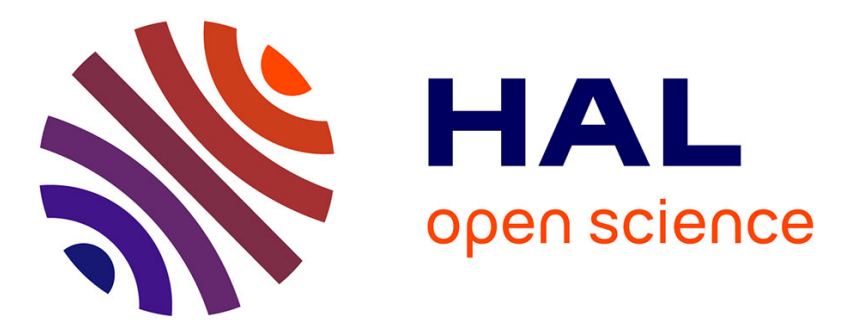

\title{
Structural optimization to maximize the flux control range of a double excitation synchronous machine
} Trung-Kien Hoang, Lionel Vido, Frederic Gillon, Mohamed Gabsi

\section{To cite this version:}

Trung-Kien Hoang, Lionel Vido, Frederic Gillon, Mohamed Gabsi. Structural optimization to maximize the flux control range of a double excitation synchronous machine. Mathematics and Computers in Simulation, 2019, 158, pp.235 - 247. 10.1016/j.matcom.2018.08.013 . hal-03486831

\section{HAL Id: hal-03486831 \\ https://hal.science/hal-03486831}

Submitted on 20 Dec 2021

HAL is a multi-disciplinary open access archive for the deposit and dissemination of scientific research documents, whether they are published or not. The documents may come from teaching and research institutions in France or abroad, or from public or private research centers.
L'archive ouverte pluridisciplinaire HAL, est destinée au dépôt et à la diffusion de documents scientifiques de niveau recherche, publiés ou non, émanant des établissements d'enseignement et de recherche français ou étrangers, des laboratoires publics ou privés.

\section{다)(1) $(5$}

Distributed under a Creative Commons Attribution - NonCommercial| 4.0 International 


\title{
Structural Optimization to Maximize the Flux Control Range of a Double Excitation Synchronous Machine
}

\author{
Trung-Kien Hoang ${ }^{1,4}$, Lionel Vido ${ }^{2}$, Frederic Gillon ${ }^{3}$, and Mohamed Gabsi ${ }^{1}$ \\ ${ }^{1}$ SATIE, ENS Cachan, 61 Av. du President Wilson, 94230, Cachan, France \\ ${ }^{2}$ SATIE, University of Cergy Pointoise, 33 bd du Port, 95000 Cergy-Pontoise, France \\ ${ }^{3}$ L2EP, Ecole Centrale de Lille, 59650 Villeneuve d'Ascq Cedex, France \\ ${ }^{4}$ Energy department, University of Science and Technology of Hanoi, Vietnam Academy of Science and Technology, 18 \\ Hoang Quoc Viet, Cau Giay, Hanoi, Vietnam
}

\begin{abstract}
This paper deals with a structural optimization to maximize the no-load flux control capability of a double excitation synchronous machine (DESM). The air-gap flux in this machine type can be regulated by controlling the field currents. In this paper, this curve in the no-load condition is referred to as the flux control range (FCR). Maximizing the gap between the minimum-flux and maximizing the maximum-flux points of this curve is targeted to improve the controlling effectiveness of the field windings, and reduce field winding's copper losses. This gap is affected by two factors: the magnetic saturation and thermal limits of the machine. Thermal analyses are rarely focused for the DESM type in the literature. The contribution of this paper is to maximize the FCR gap taking into account the thermal limitation. In addition, a general guide for the DESM design will be also discussed.
\end{abstract}

Keywords: Double excitation, electric vehicle, permanent magnet, structural optimization, synchronous machine

\section{Introduction}

A Double Excitation Synchronous machine (DESM) introduces additional field windings in a conventional permanent magnet synchronous machine (PMSM) $[1,2,3,4,5,6]$. The air-gap flux can be weakened or enhanced by adjusting field currents. It is desirable to improve the effectiveness of the field currents to reduce the copper losses associated with this flux controlling. In this paper, optimizing the air-gap flux characteristic is means to maximize the gap between the minimum-flux and the maximum-flux points, this gap is called the FCR gap. In a research conducted by Nedjar et al., the flux regulations of different DESM structures were compared, and the authors proposed one design, in which the air-gap flux can be completely canceled [1]. Amara et al. showed advantages of a parallel DESM over a series one in terms of the no-load flux control capability [7]. In [8], the FCR was maximized using a parametric design method.

All above works, however, did not consider the thermal aspect. Therefore, the obtained results probably overestimated the machine's flux controlling capability. This paper takes into account the thermal limitation so as to more comprehensively evaluate the machine's performances. Due to a numerous model evaluations, an electromagnetic model, which is constructed by using an equivalent magnetic circuit network (EMCN) method, will be adopted instead of the time-consuming finite element method (FEM). The FEM is used to validate the proposed model's accuracy. The thermal analysis is carried out by using a lumped parameter model, where the model's empirical coefficient calibrations are 
accomplished from measurements. These electromagnetic and thermal models are coupled to each other.

The design constraint to be considered in this paper is that the machine must be able to handle the rated and maximum-speed points of a torque envelop curve, which will be introduced later on. The other optimization objective is to minimize the machine's volume since it is necessary for vehicle applications. This paper will be organized as follows: firstly, the DESM topology is presented. Secondly, the machines' modeling by the EMCN and lumped parameter thermal network will be addressed. Thirdly, some design variables and theirs sensitivities are examined. Then, the optimization and result discussion will be introduced, the Multi-objective Particle Swarm Optimization (MOPSO) approach is employed for the bi-objective optimization. Lastly, a conclusion is presented.

\section{DESM prototype}

\subsection{DESM topology}

The 3-kW DESM topology is shown in Fig. 1a, which was a prototype presented by Vido et al. [2]. This model belongs to the parallel type, in which the flux sources created by field windings do not pass through the PMs. The parallel type was proved to be advantageous over the series configuration in respect of controlling the no-load flux [7]. In this prototype, two toroidal field windings carrying currents in opposite directions are placed in the stator. This arrangement, therefore, helps to avoid sliding contacts. Ferrite PMs are utilized and located in the rotor using the flux concentration principle. The magnetization directions of PMs are displayed in Fig. 1a. Due to the fact that some flux paths are truly three dimensional as detailed later on in Fig. 2 and Fig. 3, solid cores are advised to employ in some regions. With the directions of field currents being assumed in Fig. 1a, the machine is in the flux enhancing mode. Several parameters given in Table. 1 are fixed in the design optimization.

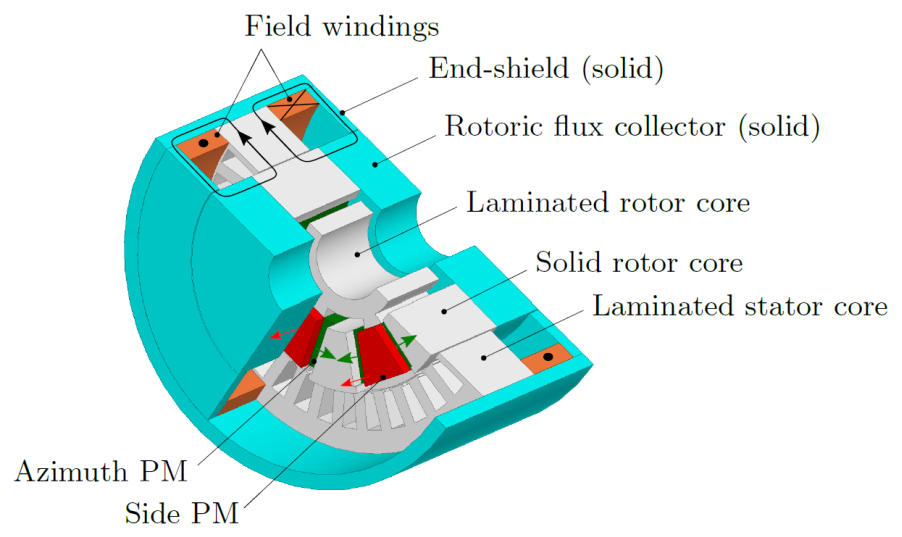

(a)

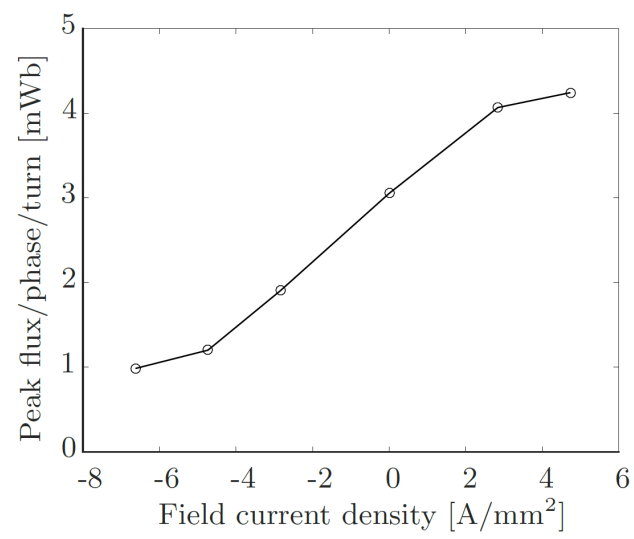

(b)

Fig. 1: (a) Reference model of DESM. (b) No-load peak flux according to the field current.

\subsection{Basic working principle}

The parallel double excitation principle of the DESM prototype owns somewhat complex flux paths as shown in Fig. 2 for bipolar flux paths and Fig. 3 for the homopolar flux paths. Simply, homopolar flux paths create only one type of pole (north or south) under the active part. Meanwhile, bipolar flux paths create north and south poles under the active part [2]. Field windings only generate homopolar flux paths, while PMs produce both types. The bipolar flux paths created by PMs in Fig. 2 are similar to those of a conventional PM machine. 
Table 1: Reference DESM topology configuration

\begin{tabular}{ll}
\hline Parameters & Value \\
\hline Number of pole pairs & 6 \\
Number of phases & 3 \\
Number of turns per armature winding & 33 \\
Number of turns per field winding & 150 \\
Number of slots/pole/phase & 1 \\
Air-gap length & $0.5 \mathrm{~mm}$ \\
Ferrite PM's residual flux density & $0.4 \mathrm{~T}$ \\
\hline
\end{tabular}

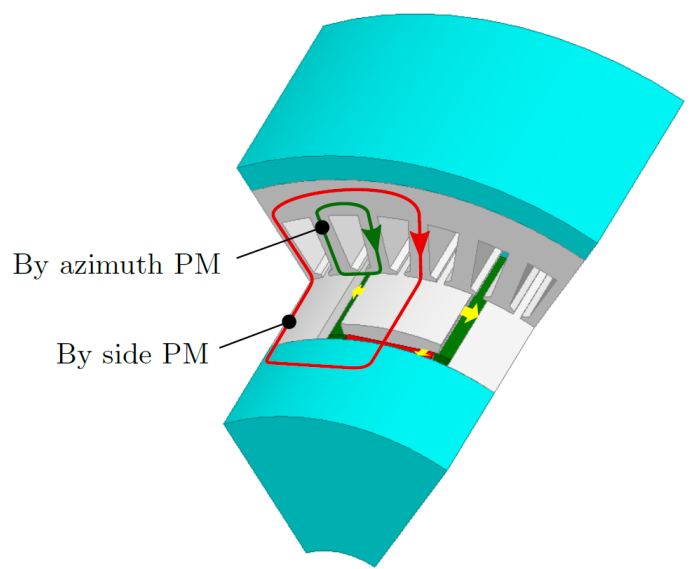

Fig. 2: Bipolar flux paths created by PMs

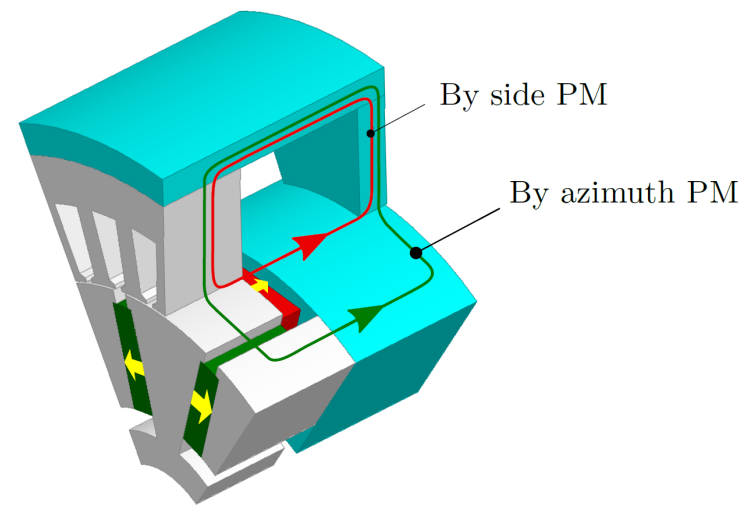

(a)

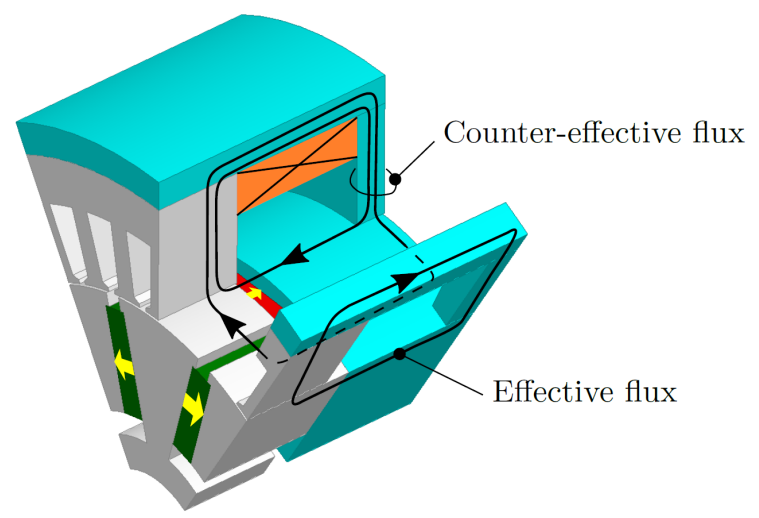

(b)

Fig. 3: Homopolar flux paths. (a) By PMs. (b) By a field winding

The field winding proposes two different kinds of homopolar flux path namely the effective and countereffective flux as shown Fig. 3b. The effective flux plays the key role for air-gap flux regulation. Meanwhile, the counter-effective flux generate flux trajectories opposite to the ones created by the effective flux. The counter-effective flux will reduce the overall flux when the stator teeth become highly saturated (in the flux enhancing mode). 


\subsection{FCR of the prototype}

The experimental FCR of the prototype is shown in Fig. 1b. The peak-flux quantity in the vertical axis's legend is meant the peak of the no-load phase flux linkage. The maximum-flux and minimum-flux points are also displayed for this particular experiment. These two points depend on the magnetic saturation and thermal limitation of the machine. It is desirable to broaden the FCR gap. As it can be seen, lowering the minimum-flux point to be close to zero represents a highly desired flux weakening capability. Regarding the electromagnetic aspect, the maximum-flux is limited by the magnetic saturation in the stator teeth, while the minimum-flux is limited by the saturation in the end-shield parts. The magnetic flux density maps corresponding to the minimum-flux and maximumflux points in Fig. 1b are displayed in Fig. 4.

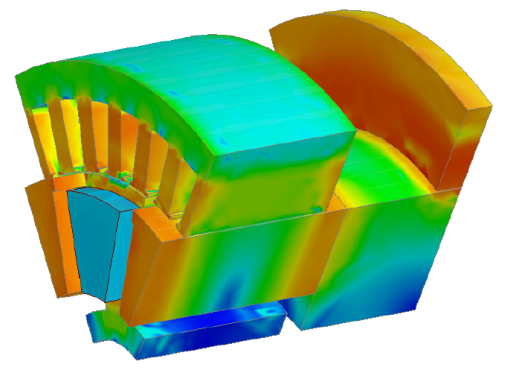

Minimum-flux point: $J_{f}=-6.6 \mathrm{~A} / \mathrm{mm}^{2}$

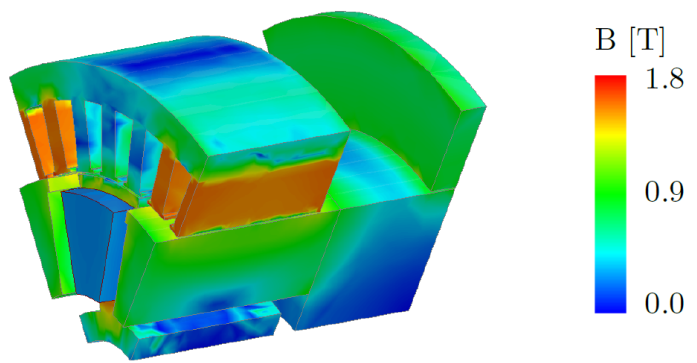

Maximum-flux point: $J_{f}=4.7 \mathrm{~A} / \mathrm{mm}^{2}$

Fig. 4: Magnetic flux density maps of the minimum-flux and maximum-flux points of the prototype. $J_{f}$ is the field current density

\section{Electromagnetic and thermal modeling}

\subsection{Electromagnetic modeling by EMCN}

The electromagnetic model is accomplished by using the EMCN method. The meshing idea of the machine's network is presented in Fig. 5a. The whole machine is decomposed into three main parts (parts 1, 3, and 5 shown in Fig. 5a). These main parts are based on the four-reluctance-block network. It means that at each node, flux paths are allowed to flow in only tangential and radial directions, i.e., a bi-directional block. In order to account for the 3-D flux paths, parts 2 and 4 work as the links between the three main parts. These two parts are based on one-reluctance blocks, where flux only flows in one direction, i.e. an unidirectional block. The nonlinearity is handled by iteratively solve the system equation using the fixed point method. The electromagnetic model provides copper and irons losses calculation as the heat source to the thermal model. The unit core loss $\left[\mathrm{W} / \mathrm{m}^{3}\right]$ is calculated as (1) [9]. This formula considers harmonic contents.

$$
P_{\mathrm{Fe}}=k_{h} f \hat{B}^{\alpha}+\frac{k_{e}}{2 \pi^{2} T} \int_{0}^{T}\left(\frac{d B}{d t}\right)^{2} d t
$$

where $k_{h}, \alpha$ and $k_{e}$ are core loss coefficients determined from sample measurements, $f$ is frequency of flux density waveform, and $T=1 / f$.

The copper loss of a winding is computed by (2).

$$
P_{\mathrm{Cu}}=I^{2} R[1+\beta(\theta-20)]
$$


where $I$ is the winding's RMS current, $R$ is the winding resistance at $20^{\circ} \mathrm{C}, \beta$ is the thermal coefficient of the winding at $20^{\circ} \mathrm{C}$, and $\theta$ is the winding temperature.

The accuracy validations against the FEM mothod are shown in Fig. 6a and Fig. 6b for the generated torque and iron loss, respectively.

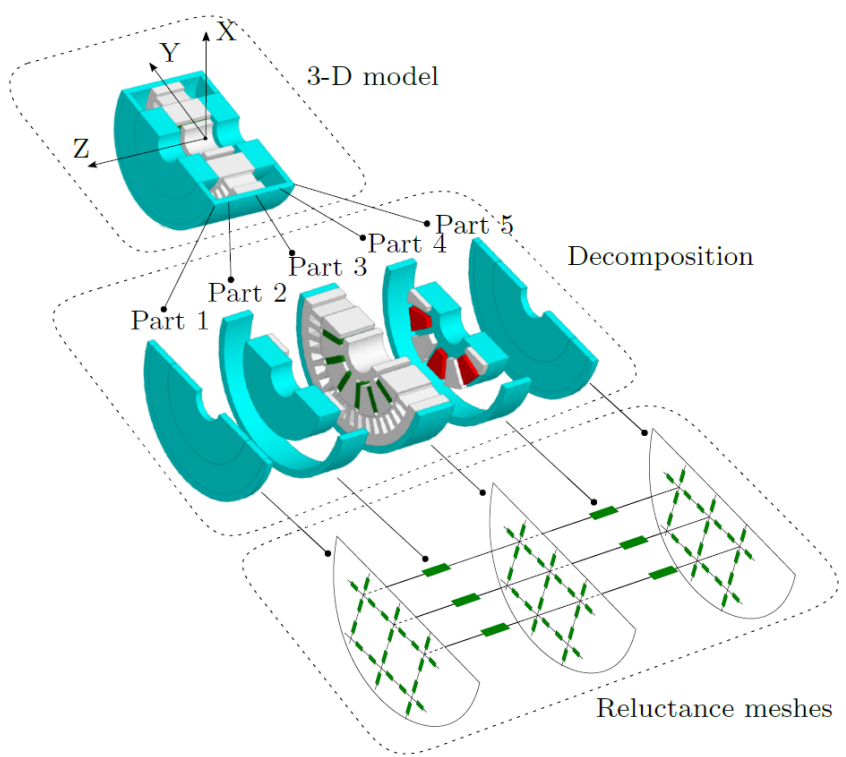

(a)

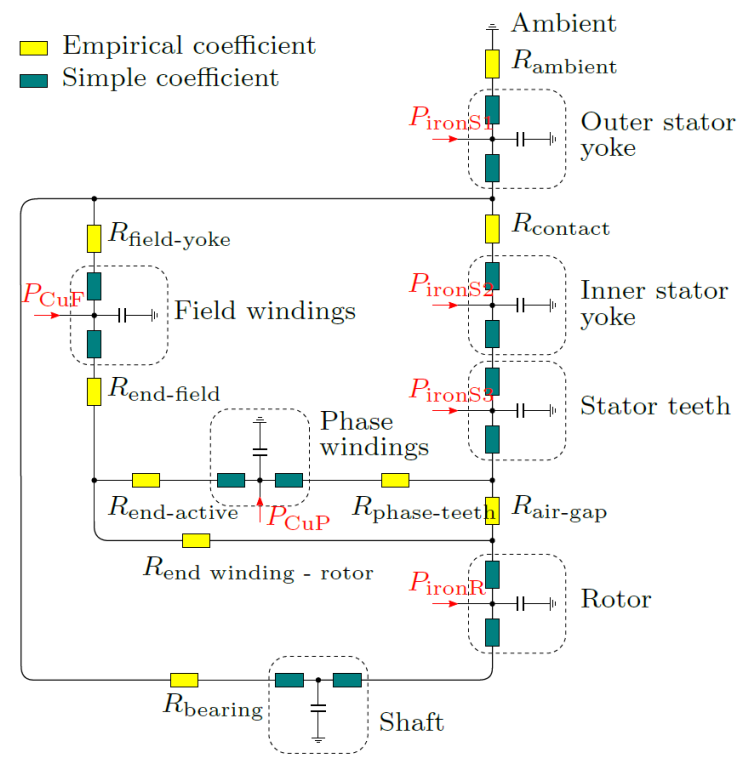

(b)

Fig. 5: Machine's modeling. (a) Meshing idea with the EMCN technique . (b) Thermal network with thermal resistances:

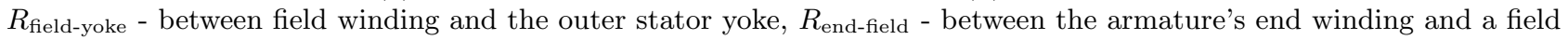

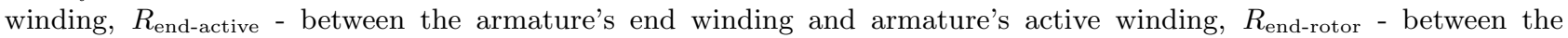
armature's end winding and rotor surface, $R_{\text {phase-teeth - between the armature's active winding and stator teeth, } R_{\text {air-gap }}}$

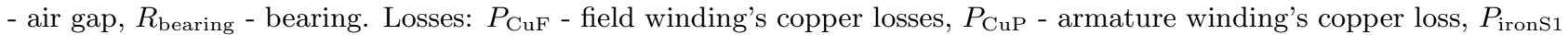
- the outer stator yoke's core loss, $P_{\text {irons2 }}$ - the inner stator yoke's core loss, $P_{\text {irons } 3}$ - the stator teeth's core loss, $P_{\text {ironR }}$ - the rotor's core loss

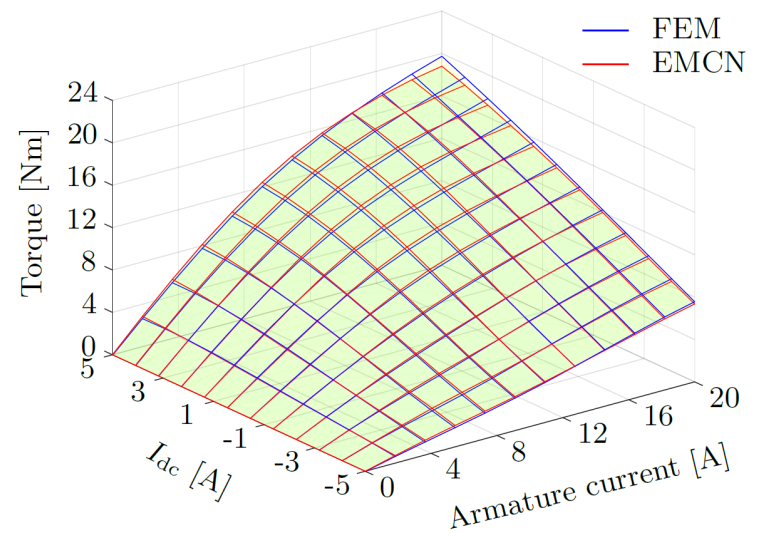

(a)

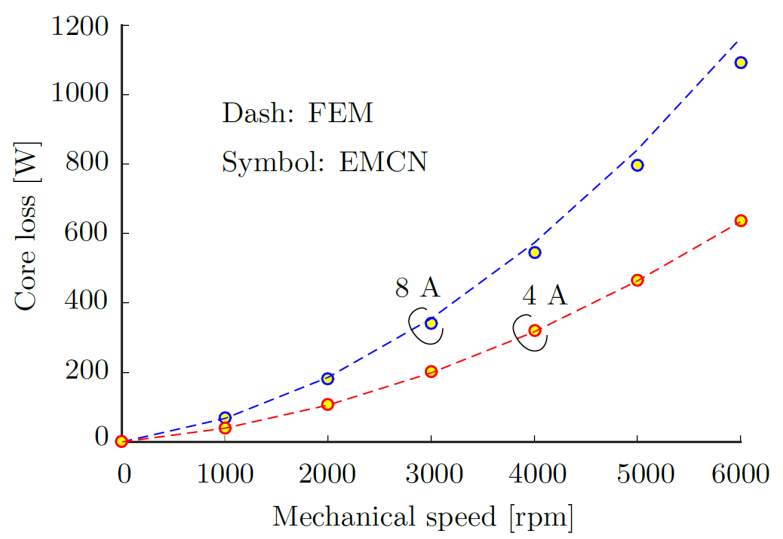

(b)

Fig. 6: Result comparison between the EMCN and FEM methods. (a) Average torque comparison. (b) Core loss according to load variation, field windings are not excited. 


\subsection{Lumped parameter thermal network}

A lumped parameter thermal model can benefit from a fast computation while maintaining a good accuracy $[10,11]$. The thermal network is shown in Fig. 5b, which is capable of dealing with the transient process by introducing thermal capacitors. As it can be seen in Fig. 5b, two types of thermal resistance are presented: one uses a simple thermal coefficient, and the others require empirical coefficients. The first type can be easily computed based on the object's geometry. The second one is more challenging, and the coefficients based on experiments or design experiences are usually required. The cooling, which is the natural air convection for the prototype, is modeled by the thermal resistance $R_{\text {ambient }}$ using the surface heat transfer coefficient. For the natural air convection, this coefficient strongly depends on the surface temperature. The heat source consists of copper losses and iron losses derived from the electromagnetic model. The mechanical loss, which consists of windage and bearing friction losses, is neglected. The winding temperature is assumed uniform across the winding. The thermal model validation in the transient mode against the experimental result is displayed in Fig. 7. In this validation, the rotor does not rotate, phase and field currents are all set to $4 \mathrm{~A}$. The winding's temperature is derived on the basis of the resistance change of that winding.

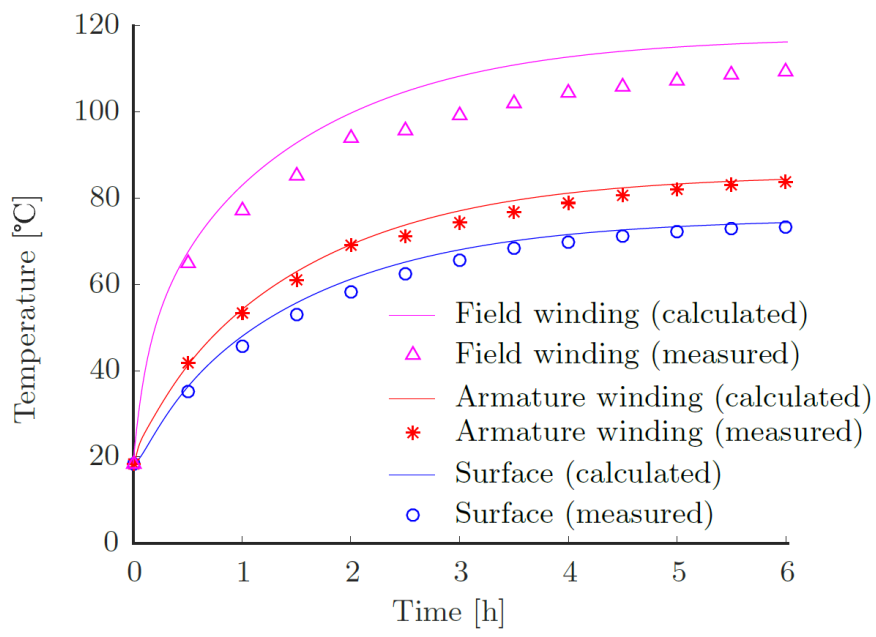

Fig. 7: Thermal model validation. Phase current $4 \mathrm{~A}$, field current $4 \mathrm{~A}$

For the design optimization, the machine is assumed to cooled by water, whose the surface heat transfer coefficient is $300 \mathrm{~W} /{ }^{\circ} \mathrm{C} / \mathrm{m}^{2}$.

The coupling between the electromagnetic and thermal models is accomplished in the way that the thermal model is to calculate windings' temperatures and the electromagnetic model is to recalculated copper losses with the newly updated windings' temperatures. The updated copper losses will update the thermal model with the recalculated copper losses. The process continues until the temperatures converge. Note that, the iron losses are assumed temperature-independent.

\section{Design variables and sensitivity analyses}

The design objectives are to maximize the FCR gap and minimize the machine's volume. The design, however, must also satisfy constraints at two operating points of a torque envelop curve: the rated and maximum speed points shown in Fig. 8, which are $(27 \mathrm{Nm}, 2000 \mathrm{rpm})$ and $(14 \mathrm{Nm}, 4000 \mathrm{rpm})$, respectively. In this section, several design variables will be presented. Their sensitivity analyses will be performed. Aiming at clearly showing influences of variables on the objectives, the constraints are not considered in this step. There are 10 design variables to be considered as shown in Fig. 9. 


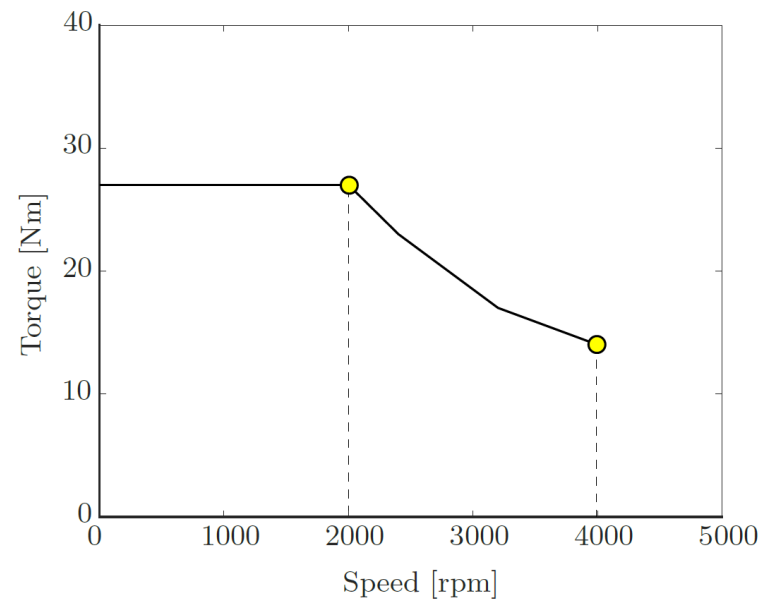

Fig. 8: The torque envelop requirement for the design constraints, the operating points for constraints are marked with circles.

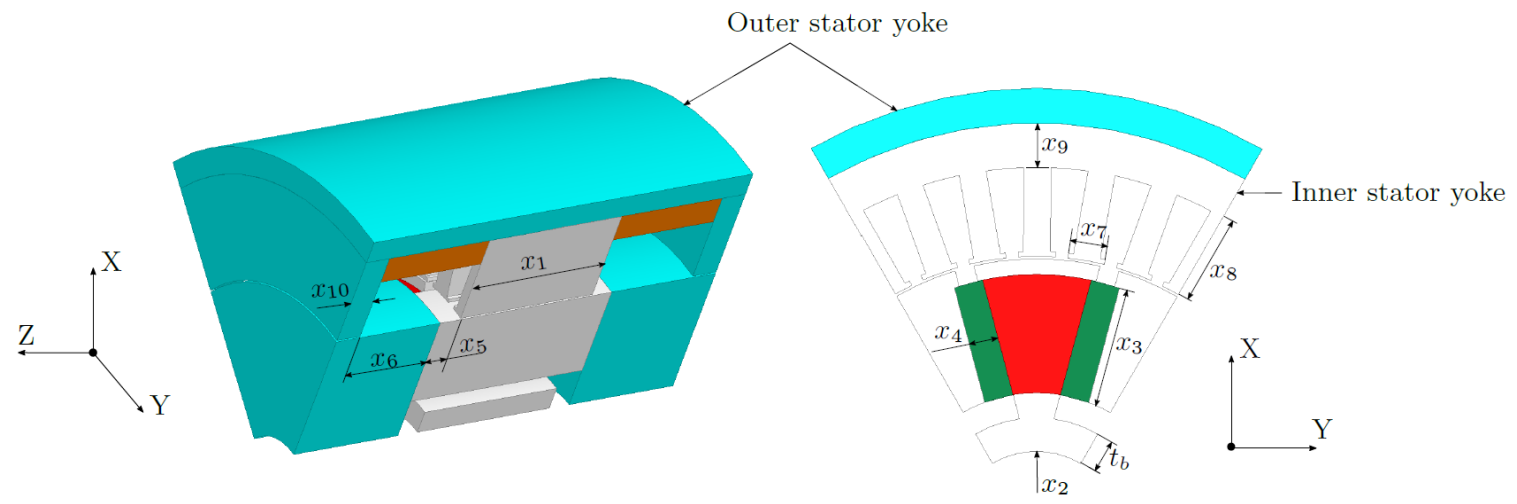

Fig. 9: Design variables. $x_{1}$-axial stack length, $x_{2}$-shaft radius, $x_{3}$-azimuth PM height, $x_{4}$-azimuth PM ratio, $x_{5}$-side PM thickness, $x_{6}$-rotoric flux collector thickness, $x_{7}$-stator tooth surface ratio, $x_{8}$-stator tooth height, $x_{9}$-inner stator yoke height, $x_{10}$-end-shield's thickness.

The variable $x_{4}$, which is the azimuth PM ratio, is calculated as the occupation of the PM at the radius level $\left(x_{2}+l_{b}\right)$, given by $(3)$.

$$
x_{4}=\frac{W_{\mathrm{A}-\mathrm{PM}}}{2 \pi\left(x_{2}+t_{b}\right) / 12}
$$

where $W_{\mathrm{A}-\mathrm{PM}}$ is the width of the azimuth $\mathrm{PM}$ and $t_{b}$ is the thickness of the rotor yoke, which is given in Fig. 9. For all designs, the ratio between $t_{b}$ and the shaft radius is assumed to be $38 \%$, which is the same as that of the prototype.

The variable $x_{7}$, which is the stator tooth surface ratio, is calculated as the portion of the total stator tooth surfaces over the periphery of the inner stator's surface. Among design variables, only two variables $x_{4}$, and $x_{7}$ do not influence the machine's volume. However, $x_{7}$ affects the armature winding's window and hence the thermal performance of the machine. All other variables will increase the machine's volume as they increase. Therefore, the sensitivity analyses will be presented only for the FCR gap minimization objective. The sensitivity analyses, which are shown in Fig. 10, are based on the dimensions of the prototype with the principle that only one variable changes at a time. Details of FCR curves are displayed in Fig. 11. The results shown in Fig. 11 are obtained by two steps:

1) The maximum field current density $J_{f \max }$ is obtained for a given machine based on the thermal 
analysis with zero armature currents since only the FCR at the no-load condition is concerned.

2) For each machine, the FCR curve is derived from a set of 20 values of the field current density equally spaced from $-J_{f \max }$ to $J_{f \max }$, the minimum-flux and maximum-flux points are determined from this set (exhaustive search approach).
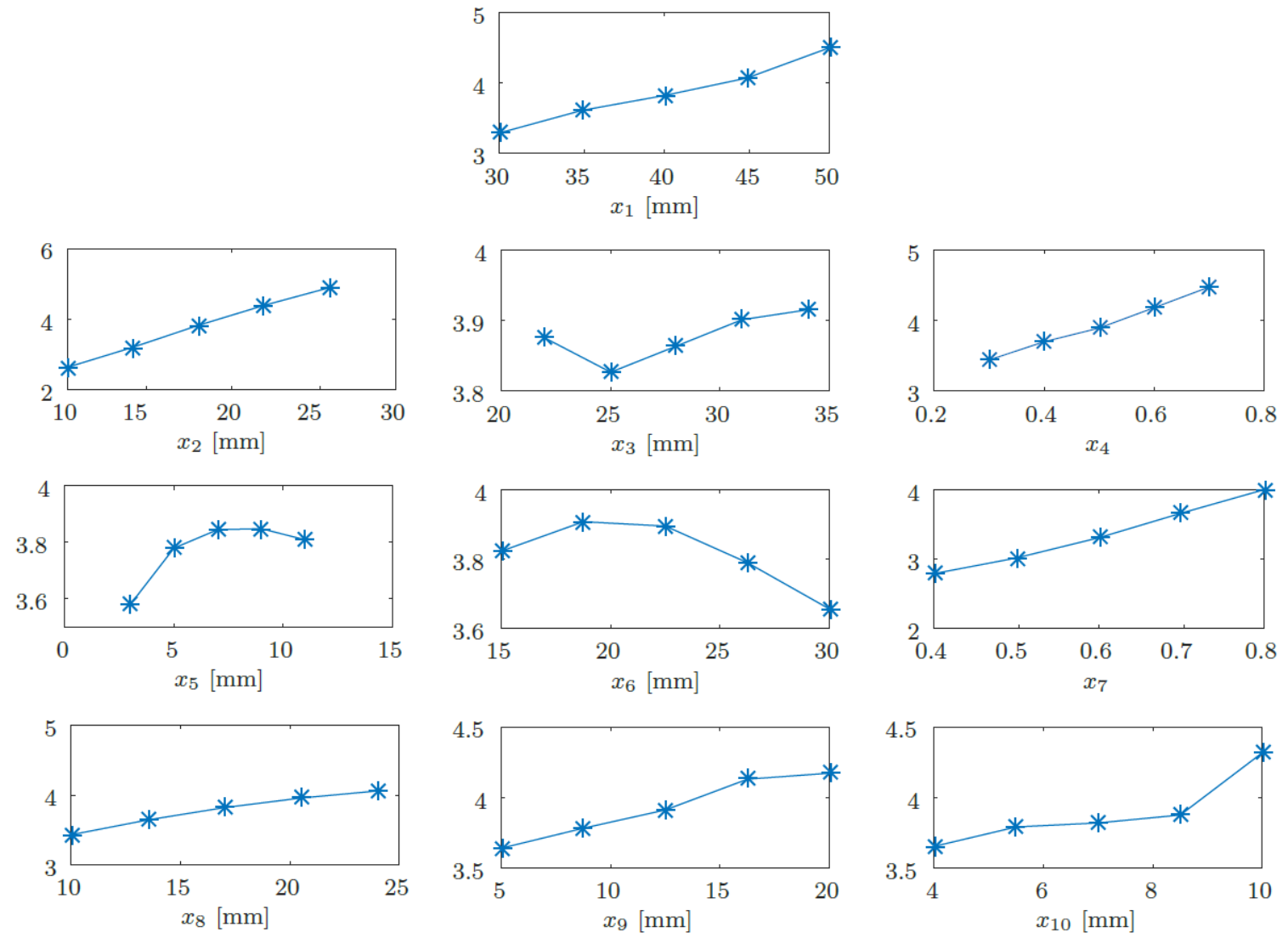

Fig. 10: Sensitivity analyses on the FCR gap. The vertical axis's labels for all sub-figures are "FCR gap [mWb]".

The influences of design variables as seen in Fig. 10 and Fig. 11 are summarized in the following. Note that, the maximum-flux point is limited due to the magnetic saturation in the stator teeth, and the minimum-flux point is limited due to the magnetic saturation in the end-shields as already shown in Fig. 4.

$x_{1}$ - Axial stack length:

Increasing this value will increase both the minimum-flux and maximum-flux points as the flux contribution from azimuth PM increases. In addition, the saturation in the stator teeth will be mitigated, the FCR gap will increase as a result.

$x_{2}$ - Shaft radius:

As the shaft radius increases, the air-gap diameter will increase. In addition, the stator tooth surface will increase as well. So the effectiveness of the field winding will increase in both flux weakening and flux enhancing. In overall, the FCR gap increases as the $x_{2}$ increases.

$x_{3}$ - Azimuth PM height:

Increasing this height will increase the air-gap diameter. Therefore, the minimum-flux and 

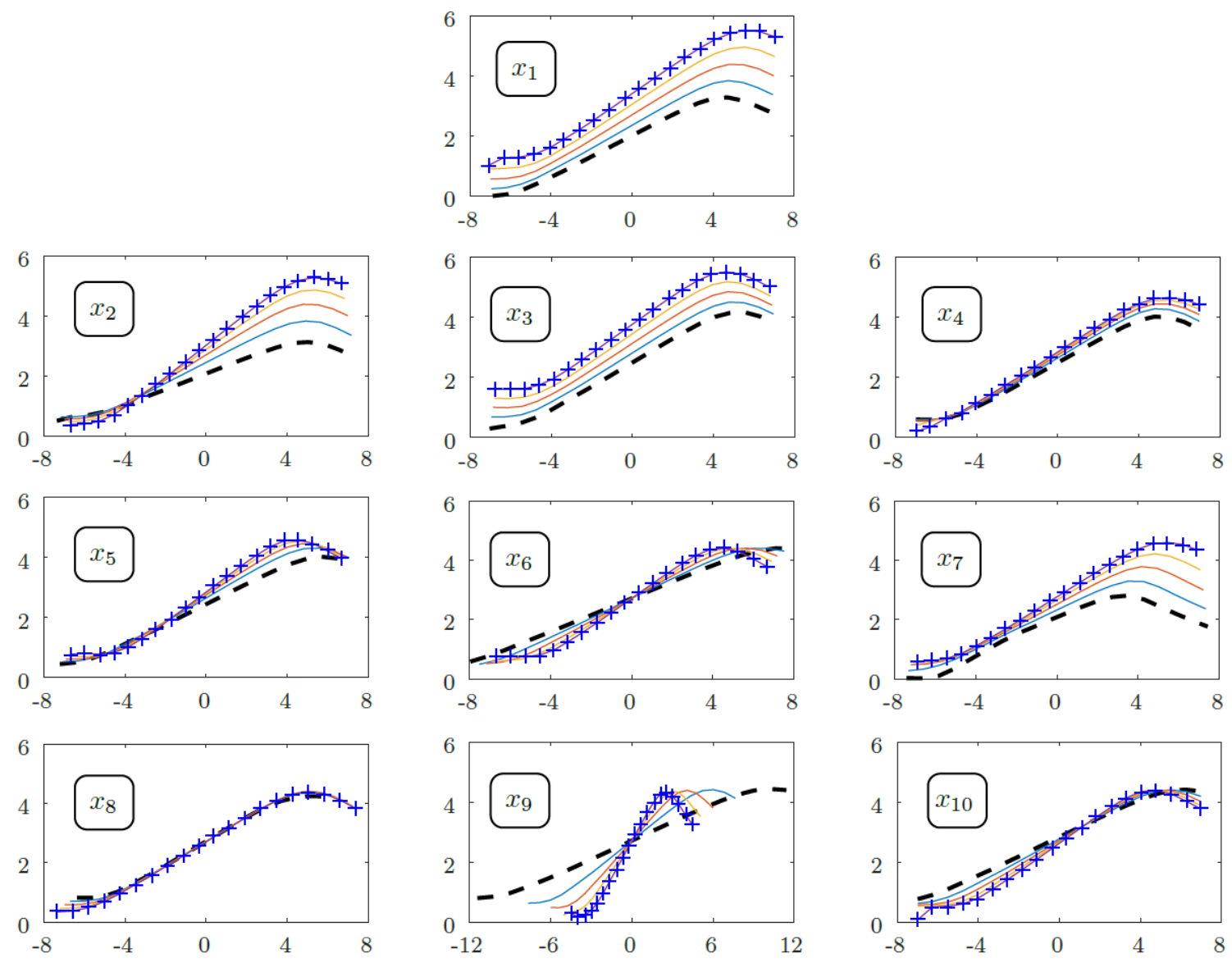

Fig. 11: Sensitivity analyses on the FCR curves. The vertical axis's labels for all sub-figures are "Peak flux/phase/turn [mWb]" and the horizontal axis's labels are "Field current density $\left[\mathrm{A} / \mathrm{mm}^{2}\right]$. Curves corresponding to the lower and upper variable bounds are marked with dash (-) and plus (+) symbols, respectively.

maximum-flux all increase. In addition, the field winding's winding slightly increases leading to early saturations as seen in Fig. 11.

$x_{4}$ - Azimuth PM ratio:

Increasing this PM ratio will lower the counter-effective flux created by the field windings, and the FCR gap is improved.

$x_{5}$ - Side PM thickness:

The effect of increasing this thickness is similar to that of the azimuth PM ratio. In addition, increasing this value will increase the field winding's window, and the field winding's magnetomotive force (MMF) increases (with the same amount of field current density). Therefore, the saturation occurs earlier as shown in Fig. 11.

$x_{6}$ - Rotoric flux collector thickness:

The main effect of increasing this thickness is to increase the field winding's window. As the result, the minimum-flux and maximum-flux values are almost the same for different thicknesses, just the saturation occurs earlier when this thickness increases.

$x_{7}$ - Stator tooth surface ratio:

Increasing this value has a similar impact as increasing the axial stack length $x_{1}$, the saturation is mitigated and the FCR gap increases. 
$x_{8}$ - Stator tooth height:

Increasing this value will make the machine bigger, the saturation in the stator teeth does not change so that the maximum-flux stays almost constant. However, as the field winding's window slightly gets larger, a high field current density is allowed and a lower minimum-flux can be achieved. Therefore, the FCR gap increases as $x_{9}$ increases.

$x_{9}$ - Inner stator yoke height:

Increasing this value will increase the field winding's window as well as the field winding's MMF (with the same field current density). This explains the "narrow-area" effect of $x_{9}$ on the FCR. Moreover, the total field winding's MMF is able to reach a higher value leading to a lower minimum-flux point. The maximum-flux point remains unchanged as the stator teeth's saturation does not vary. Therefore, the FCR gap increases as $x_{9}$ increases.

$x_{10}$ - End-shield's thickness:

Increasing this thickness will lower the air-gap reluctance below the end-shields, this results in a less field current is required to regulate the air-gap flux.

In the following, a bi-objective optimization will be carried out taking into account the torque envelop requirement constraint.

\section{Optimization, results and discussion}

\subsection{Optimization formulation}

Since there are constraints for two operating points (rated and maximum-speed points), two subprocedures are required for each machine. These two sub-procedures aim at ensuring if the machine is able to generate the required torques at required speeds without violating the winding's temperature and voltage limits. Because the sub-procedure is not an optimization, a run with 50 randomly-chosen control variable sets $\left(d-, q-\right.$ axis armature currents and the field current density $\left.J_{f}\right)$ is examined to decide if the machine satisfy the constraints. This approach is considered as a compromise between the computation time and the optimization quality. As the machine satisfies two constraints, the FCR gap is obtained based on the approach presented in section 4. The machine's volume is easily computed based on the stator outer diameter and machine's total axial length, i.e., the stack length plus the field windings' width and end-shields' thickness.

The optimization is formulated as (4). Note that, the maximizing FCR gap objective is transformed to minimizing "- FCR gap" to have a min-min optimization problem, which is common in optimization demonstrations.

$$
\begin{array}{ll}
\text { Minimize } F(X)=\left[\begin{array}{c}
- \text { FCR gap } \\
\text { Volume }
\end{array}\right] \\
\text { s.t. Point 1: }(27 \mathrm{Nm}, 2000 \mathrm{rpm}): T_{\max } \leqslant 155^{\circ} \mathrm{C}, V_{\max } \leqslant 150 \mathrm{~V} \\
\text { Point 2: }(14 \mathrm{Nm}, 4000 \mathrm{rpm}): T_{\max } \leqslant 155^{\circ} \mathrm{C}, V_{\max } \leqslant 150 \mathrm{~V} \\
\text { Variables' domain: } \\
30 \mathrm{~mm} \leq x_{1} \leq 50 \mathrm{~mm} & 13 \mathrm{~mm} \leq x_{6} \leq 30 \mathrm{~mm} \\
15 \mathrm{~mm} \leq x_{2} \leq 25 \mathrm{~mm} & 0.4 \leq x_{7} \leq 0.8 \\
24 \mathrm{~mm} \leq x_{3} \leq 30 \mathrm{~mm} & 15 \mathrm{~mm} \leq x_{8} \leq 25 \mathrm{~mm} \\
0.35 \leq x_{4} \leq 0.8 & 9 \mathrm{~mm} \leq x_{9} \leq 18 \mathrm{~mm} \\
6 \mathrm{~mm} \leq x_{5} \leq 10 \mathrm{~mm} & 5 \mathrm{~mm} \leq x_{10} \leq 9 \mathrm{~mm}
\end{array}
$$




\subsection{Optimization result and FEM validation}

The MOPSO technique [12] is used for the optimization. This optimization technique is an evolutionary computation optimization (a search method based on a natural system) developed by Kennedy and Eberhart [13]. A combination of 60 particles and 50 iterations, i.e. 3000 machines are examined, the computation time is 87 hours on a quad-core, $2.93 \mathrm{GHz}, 12 \mathrm{~Gb}$ of RAM. Note that, this computation time includes two sub-procedures of 50 sets of control variables for each machine. The optimization result, which is presented in a non-dominated pareto-front, is shown in Fig. 12. Note that, due to the stochastic nature of the MOPSO technique, 3 optimization runs were performed to obtained the result.

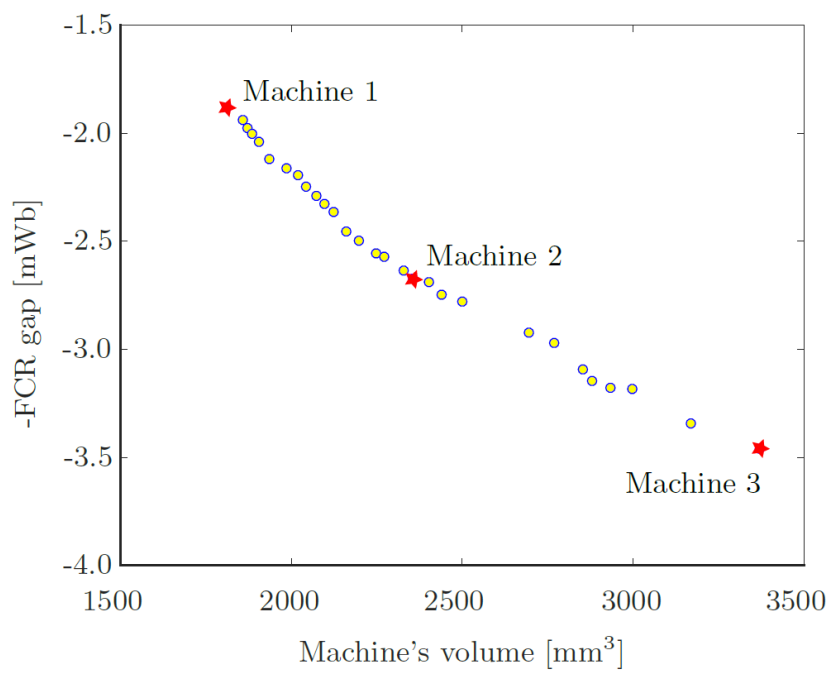

Fig. 12: Non-dominated solutions optimization result

In order to examine in detail the solutions presented in Fig. 12, three machines ("machine 1", "machine 2", and "machine 3" in Fig. 12) are extracted as shown in Fig. 13. The corresponding parameters are shown Table. 2.
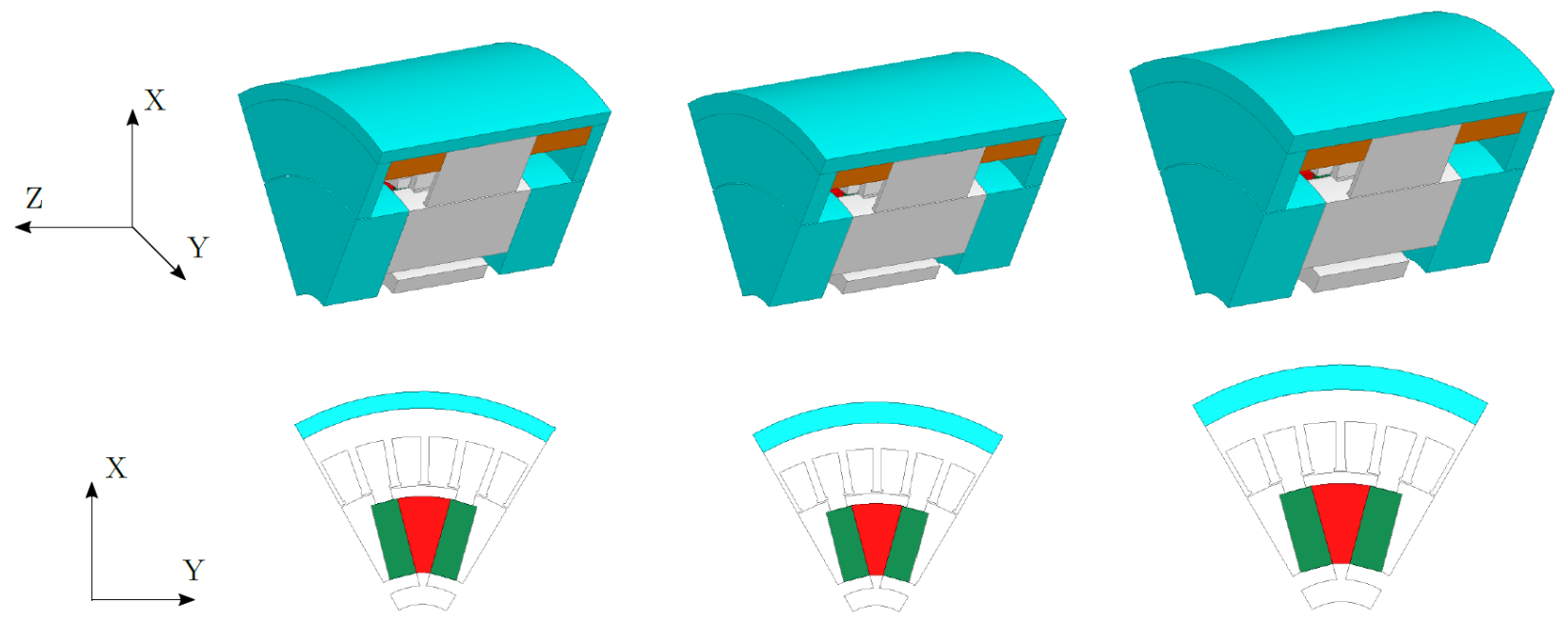

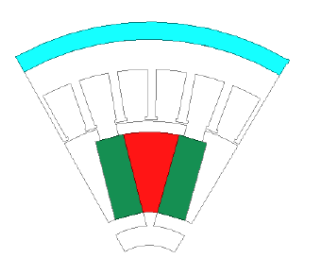

Machine 1

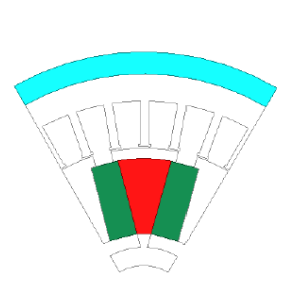

Machine 2

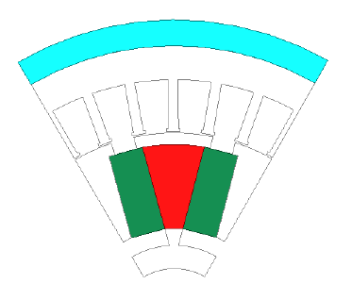

Machine 3

Fig. 13: Three machines extracted from non-dominated solutions in Fig. 12 
Table 2: Dimensions of extracted machines in Fig. 12

\begin{tabular}{llll}
\hline Variable & Machine 1 & Machine 2 & Machine 3 \\
\hline$x_{1}[\mathrm{~mm}]$ & 34 & 38.3 & 36.6 \\
$x_{2}[\mathrm{~mm}]$ & 15 & 16.1 & 19.8 \\
$x_{3}[\mathrm{~mm}]$ & 24 & 24.9 & 27.3 \\
$x_{4}$ & 0.8 & 0.8 & 0.79 \\
$x_{5}[\mathrm{~mm}]$ & 6 & 8.6 & 9.5 \\
$x_{6}[\mathrm{~mm}]$ & 15 & 15 & 17.2 \\
$x_{7}$ & 0.4 & 0.4 & 0.4 \\
$x_{8}[\mathrm{~mm}]$ & 15 & 15.1 & 16.8 \\
$x_{9}[\mathrm{~mm}]$ & 9 & 9 & 11 \\
$x_{10}[\mathrm{~mm}]$ & 5.2 & 7.2 & 8.4 \\
\hline Outer stator diameter $[\mathrm{mm}]$ & 163.2 & 173.2 & 200.6 \\
Total axial length $[\mathrm{mm}]$ & 86.4 & 100.0 & 106.5 \\
\hline
\end{tabular}

As seen, the variable $x_{4}$, which is the azimuth PM ratio, prefers the upper boundary of its domain. This is in accordance with the sensitivity analyses of $x_{4}$ presented above: increasing this value will lower the counter-effective flux created by the field windings. Therefore, the FCR gap is kept high. The variable $x_{7}$, which is the stator tooth surface ratio, prefers to stay at the lower boundary of its domain. This contradicts the expectation of the variable's trend from its sensitivity analysis, which claimed that increasing this value will lower the magnetic saturation in the stator teeth and the FCR gap increases. However, the small value of $x_{7}$ can be explained by the fact that it leaves more room for the armature windings to satisfy the two operating points' torque constraints.

The FEM validations on the FCR curves are shown in Fig. 14. As observed, a good accordance is reported between the EMCN and FEM results. Different ranges for the field current density $J_{f}$ is due to the different field winding's windows as well as other machine's dimensions. However maximum field current densities of these three machines are close to each other. As it will be seen for the "machine 3", the air-gap flux due to PMs can be nearly canceled out, which is highly desirable for the flux weakening control.

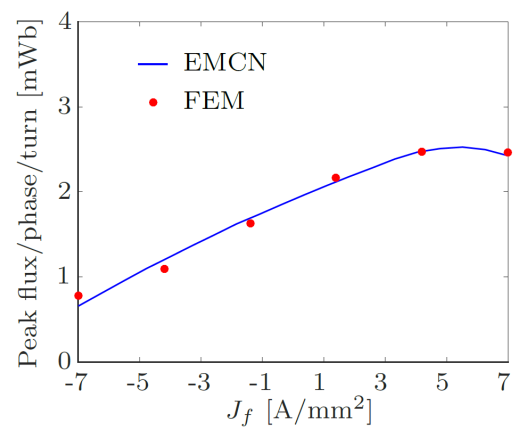

(a)

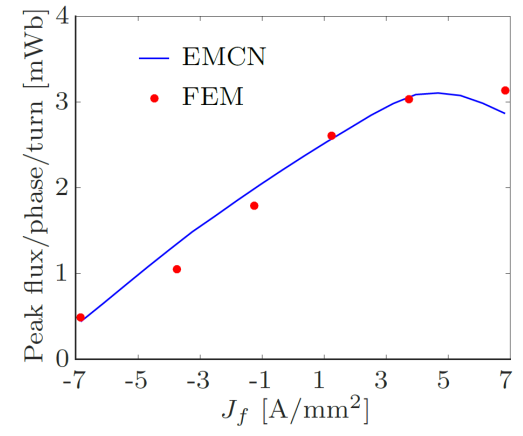

(b)

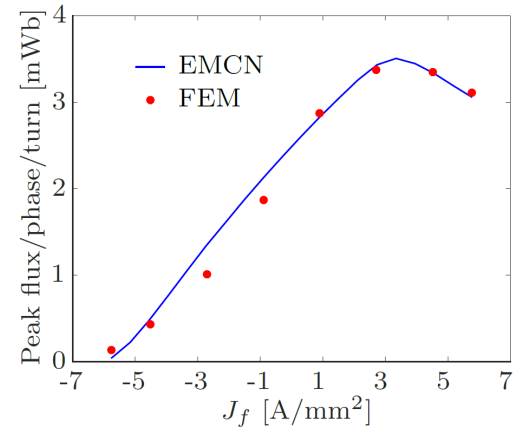

(c)

Fig. 14: FEM validation for 3 machines marked in Fig. 12. (a) Machine 1. (b) Machine 2. (c) Machine 3.

Another criterion can be considered to evaluate the effectiveness of the field windings. This criterion is defined as the slope $M$ of the FCR curve expressed by (5). A high value of $M$ means that certain flux can be regulated at the expense of a small amount of field windings' copper losses. Table. 3 
summarizes slopes of FCR curves for the three extracted machines, results are obtained by using the EMCN method.

$$
M=\frac{\text { FCRgap }}{J_{f 2}-J_{f 1}} \quad\left[\mathrm{mH} \cdot \mathrm{mm}^{2}\right]
$$

where $J_{f 2}$ and $J_{f 1}$ are field current densities corresponding to the the maximum-flux and minimum-flux points, respectively.

Table 3: Summary of the slopes of various FCR curves

\begin{tabular}{llll}
\hline & Machine 1 & Machine 2 & Machine 3 \\
\hline Maximum flux [mWb] & 2.53 & 3.11 & 3.51 \\
Minimum flux [mWb] & 0.66 & 0.44 & 0.04 \\
$M\left[\mathrm{mH} . \mathrm{mm}^{2}\right]$ & 0.15 & 0.23 & 0.38 \\
\hline
\end{tabular}

\subsection{General discussion}

A DESM is able to regulate the air-gap flux more flexibly compared to conventional PM machines. However, it is accomplished at the expense of a bigger volume and more cost due to the presence of additional field windings. The working principle should be also more complicated especially in case of the parallel configuration as with the DESM topology presented in this paper. An interesting point in choosing machine's dimensions in order to maximize the FCR gap is about the width ratio (or the thickness) of the azimuth PM. As pointed out, this thickness should be designed as high as possible. This might contradict the conventional PM machine designs because the flux weakening of those machines becomes more difficult as the $d$-axis armature current must pass through this PM. As with the DESM, the flux control can be handled much easier by field windings. Moreover, having a thick azimuth PM helps to reduce the counter-effective flux of the field windings as discussed. This design rule is applicable to the parallel-flux-combination cases with the presence of the counter-effective flux from field windings passing though PMs.

Another aspect to be considered when designing the DESM is to better design the thermal contact between the field windings and the iron core. It helps reduce the field windings' copper losses. However, concerning the capability to improve the flux control range, it requires an elaborate analysis since the magnetic saturation might occur ealier than the thermal constraint violation.

\section{Conclusion}

An optimization with an objective aiming at improving the no-load flux control range of a DESM has been performed. Some critical operating points of a torque envelop curve were used as constraints. The complexity in both electromagnetic and thermal aspects were well handled by using equivalent circuit networks. One configuration is also found to nearly cancel out the PMs' flux. In the future works, a more comprehensive study to evaluate performances of the DESM in a specific vehicle application will be carried out.

\section{References}

[1] B. Nedjar, S. Hlioui, Y. Amara, L. Vido, M. Gabsi, and M. Lecrivain, "A new parallel double excitation synchronous machine," IEEE Transactions on Magnetics, vol. 47, no. 9, pp. 2252-2260, Sept 2011. 
[2] L. Vido, M. Gabsi, M. Lecrivain, Y. Amara, and F. Chabot, "Homopolar and bipolar hybrid excitation synchronous machines," in IEEE International Conference on Electric Machines and Drives, May 2005, pp. 1212-1218.

[3] J. Tapia, F. Leonardi, and T. Lipo, "Consequent-pole permanent-magnet machine with extended field-weakening capability," IEEE Transactions on Industry Applications, vol. 39, no. 6, pp. 17041709, Nov 2003.

[4] F. Liang and J. Miller, "Permanent magnet electric machine with flux control," Apr. 16 2002, US Patent 6,373,162.

[5] D. Akemakou, "Dual excitation electrical machine, and especially motor vehicle alternator," Mar. 14 2000, US Patent 6,037,691.

[6] T. Radomski, "Alternating current generator," Sep. 25 1990, US Patent 4,959,577.

[7] Y. Amara, S. Hlioui, R. Belfkira, G. Barakat, and M. Gabsi, "Comparison of open circuit flux control capability of a series double excitation machine and a parallel double excitation machine," IEEE Transactions on Vehicular Technology, vol. 60, no. 9, pp. 4194-4207, Nov 2011.

[8] K. Hoang, L. Vido, M. Gabsi, and F. Gillon, "Flux control range broadening and torque ripple minimization of a double excitation synchronous motor," IEEE Transactions on Magnetics, vol. 53, no. 1, pp. 1-10, Jan 2017.

[9] D. Lin, P. Zhou, W. Fu, Z. Badics, and Z. Cendes, "A dynamic core loss model for soft ferromagnetic and power ferrite materials in transient finite element analysis," IEEE Transactions on Magnetics, vol. 40, no. 2, pp. 1318-1321, March 2004.

[10] J. Nerg and V. Ruuskanen, "Lumped-parameter-based thermal analysis of a doubly radial forcedair-cooled direct-driven permanent magnet wind generator," Mathematics and Computers in Simulation, vol. 90, no. Supplement C, pp. 218 - 229, 2013.

[11] D. Fodorean, A. Djerdir, I. A. Viorel, and A. Miraoui, "A double excited synchronous machine for direct drive application: Design and prototype tests," IEEE Transactions on Energy Conversion, vol. 22, no. 3, pp. 656-665, Sept 2007.

[12] J. Aubry, H. B. Ahmed, and B. Multon, "Bi-objective sizing optimization of a pm machine drive on an operating profile," in Proceedings, International Conference on Electrical Machines (ICEM), Sept 2010, pp. 1-7.

[13] J. Kennedy and R. Eberhart, "Particle swarm optimization," in Proceedings, IEEE International Conference on Neural Networks, vol. 4, Nov 1995, pp. 1942-1948 vol.4. 